\title{
ВЛИЯНИЕ СТЕРЕОТИПОВ НА ПРОЦЕСС МЕЖКУЛЬТУРНОЙ КОММУНИКАЦИИ
}

\section{INFLUENCE OF STEREOTYPES ON THE PROCESS OF INTERCULTURAL COMMUNICATION}

\section{E. Krivosheeva \\ V. Lukovtseva}

Summary: The article discusses the issues of stereotypes and their role in teaching intercultural communication.

Very often, stereotypes can lead to discrimination that turns inaccurate and negative feelings into actions against certain individuals or groups. However, this can be prevented if aspects of cross-cultural communication are correctly added to the curriculum in specialized schools and gymnasiums in order to avoid cultural shock during subsequent communication with a native speaker.

Keywords: culture, intercultural communication, stereotype, ethnocentrism.

\author{
Кривошеева Елена Николаевна \\ Стариий преподаватель, РУДН, г. Москва \\ krivosheeva.elena.1969@mail.ru \\ Луковцева Виктория Николаевна \\ Старший преподаватель, РУДН, г. Москва \\ luvina@mail.ru
}

Аннотация: В статье рассмотрены вопросы о стереотипах и их роли в обучении межкультурной коммуникации.

Очень часто стереотипы могут привести к непониманию, и даже к дискриминации в коллективе (школы, университета и т.д.). Однако это можно предотвратить, если грамотно добавить в программу обучения в специализированных школах и гимназиях аспекты межкультурной коммуникации во избежание культурного шока при последующем общении с носителем языка.

Ключевые слова: культура, межкультурная коммуникация, стереотип, этноцентризм.

зывать, что общение - это не просто обмен информацией, мнениями, а также стереотипные образы культуры других народов.

Существуют анекдоты о стереотипах того или иного этноса, отражающие характерные черты и отношение народа и или социальной группы. Наиболее распространенным является тот, который про «Ад и Рай». Эта шутка звучит так: «Рай - это место, где: полиция - британцы, шеф-повара - французы, любовники - итальянцы, а все организовано немцами. Ад - это место, где: полиция французы, шеф-повара - британцы, любовники - немцы, а все организовано итальянцами.» Тот факт, что люди в каждой из указанных стран могут смеяться над этим, говорит о том, что в шутке есть доля правды и стереотипы могут быть интернационалными внутри одной расовой группы.

Ведь стереотип - это фиксированное, слишком обобщенное представление о конкретной группе людей или совместной культуре. Система социальных стереотипов носителей той или иной культуры отражает особенности национального характера. Поэтому стереотипы представляют особый интерес для исследования. Термин «социальный стереотип», введенный в 1922 г. американским журналистом У. Липпманом - создателем теории «стереотипизации», обозначает упрощенное, схематизированное, зачастую искаженное, характерное для сферы обыденного сознания представление о каком-либо социальном объекте. 
Социальный стереотип фиксирует в себе некоторые, иногда несущественные черты объекта, обладающие относительной устойчивостью. «Стереотипизация» служит одной их важнейших характеристик межгруппового и межличностного восприятия и отражает «схематичность», свойственную этой форме социальной перцепции».

Независимо от того, насколько точен стереотип, он основан на некоторой реальности. В тот момент, когда мы понимаем, что вступаем в контакт, люди начинают искать сходства с собой. В целом, это очень естественная склонность к тому, чтобы стремиться быть рядом с теми, с которыми у нас общие взгляды, привычки или языки. Чем больше точек соприкосновения, тем более комфортно себя чувствуем и тем быстрее можем установить новые отношения.

Что действительно важно, так это то, что когда нам не удается найти точку соприкосновения, хватит ли у нас смелости преодолеть возникшую тревогу и идти вперед или все вместе откажемся от взаимодействия с неизвестным? Независимо от нашего выбора, при столкновении с неопределенностью, в результате этой конфронтации наверняка сформируются стереотипы. Мы склонны думать о них негативно. Тем не менее, все мы виновны в том, что помещаем других вне поля восприятия, несмотря на то, что наши знания о них - лишь зерно правды.

Также по-разному проявляются и стереотипы-представления. Например, Корейцы говорят: «Жена должна быть как лиса, а муж - как медведь», имея в виду, что жена должна быть умной, гибкой в общении и хитрой, а медведь сильным. На первый взгляд ассоциации, связанные с этими животными у корейцев, схожи с ассоциациями у русских. Но при ближайшем рассмотрении оказывается, что русская лиса - это в первую очередь эталон хитрости, и это качество воспринимается русскими скорее, как отрицательное. Медведь для русских в первую очередь неуклюж, а уже потом все остальное.

Одним из известных стереотипов русского русских это сопоставление жены с шеей, которая умело руководит своим мужем.

Национальные (этнокультурными) стереотипы подразделяются на «автостереотипы» - представление о своем народе и о своей культуре и «гетеростереотипы», схематично обобщающие взгляды на другие народы и культуры. Например, француз для немцев - эталон жадности, для итальянцев - спеси и снобизма, для русских - галантности. Немец для русских - пример пунктуальности, итальянец - эмоциональности и вокального мастерства, англичанин - чопорности и сдержанности.

Стереотип как феномен рассматривается с разных точек зрения. Неоднозначно и отношение к стереотипам. Например, О.А. Леонтович считает, что «стереотипы- упрощенные ментальные репрезентации различных категорий людей, преувеличивающие моменты сходства между ними и игнорирующие различия. «Стереотипизация» предполагает статичный взгляд на общество и человека, неумение воспринимать уникальность человеческой личности, стремление свести всех людей к ограниченному числу типов со стандартным набором характеристик» [4, с. 236]. Определение О.А. Леонтович дано в контексте проблем межкультурной коммуникации. О.А. Леонтович считает, что «различные виды стереотипов, существующие на уровне языка, способны создавать помехи в межкультурной коммуникации.

Возникновению стереотипов способствуют две тенденции человеческого сознания: 1) конкретизация - ассоциирование абстрактных понятий с какимито конкретными образами; 2) упрощение - выделение нескольких признаков в качестве ведущих для обозначения нескольких явлений. Они формируются как в процессе неорганизованной передачи информации (слухи, анекдоты, поговорки), так и в процессе непосредственного межнационального общения, строятся на предубеждениях, уходящих корнями в историю, передаются художественной литературой и фольклором [10]. При изучении роли стереотипов в межкультурной коммуникации необходимо помнить о том, что стереотипы всегда национальны. Правда, иногда можно найти аналоги в разных культурах. Но таким случаям нужно уделять особое внимание, поскольку совпадая в целом, эти стереотипы могут различаться деталями, имеющими большое значение для успешного общения. Различия в стереотипах, бытующих в разных культурах, касаются многих аспектов. Например, темы бесед: о чем можно, а о чем нельзя говорить с представителями других культур, отношение ко времени, поведение представителей разных культур в общественных местах и т.д.

Наш разум развился, чтобы провести этот жизненно важный процесс - управлять своей жизнью, развивать навыки и завоевывать мир.

В любом случае создаются стереотипы, поскольку это универсальный процесс, как на коллективном, так и на индивидуальном уровне.

Однако главная проблема этого, казалось бы, естественного процесса заключается в том, что, хотя наш мозг может быть достаточно искусным для классификации неодушевленных объектов, мы сталкиваемся с проблемами при классификации людей, потому что люди намного сложнее, чем объекты.

Во-первых, стереотипы заманивают нас в ловушку, которая отфильтровывает всю информацию, не соот- 
ветствующую нашим представлениям. Люди склонны пренебрегать фактами, которые ставят под сомнение убеждения, особенно когда нет ресурсов для противостояния этой информации. Стереотипы очень стабильны и их трудно изменить. Даже когда сталкиваемся со случаями, которые противоречат им, мы склонны считать, что это просто исключение из правил.

Например, если вы придерживаетесь распространенного стереотипа о том, что все американцы высокомерные, поэтому при встрече с дружелюбным и улыбчивым американцем, с большей вероятностью придете к выводу, что это всего лишь первое впечатление, и этот человек не является тем, кем хочет показаться при первом знакомстве. Кроме того, этот выборочный фильтр будет усиливать только ту информацию, которая соответствует вашим предположениям. Одним словом, вы видите только то, что хотите увидеть. Следовательно, вас вводят в заблуждение при принятии решений, основанных на ложных убеждениях.

Во-вторых, стереотипы могут создавать само-исполняющиеся пророчества из-за связи между верой и поведением. По сути, на вашу характеристику в обществе будет влиять то, что люди обычно думают о вашей группе (окружении), и, следовательно, косвенно думают о вас.

Например, когда европейцам напоминают о том, что они обладают более низкими спортивными способностями, чем, например, афроамериканцы, они также демонстрируют худшие результаты, чем те, которые не были осведомлены об этом стереотипе.

Точно так же женщины думают в отношении того, что они менее способными, чем мужчины, в технических и математических работах, но это миф, который оказался ошибочным, поскольку женщины могут решать математические проблемы наравне с мужчинами. Этот эффект стереотипирования может вести нас в заблуждение

Вместо этого он ставит нас под сомнение наши собственные способности и приписывает эту слабость нашему возрасту, расе, полу, национальности и т.д. Наконец, есть и положительные стереотипы. Если логически подумать, то, если отрицательный стереотип заставляет людей работать хуже, чем они могут, то положительный заставляет их работать лучше. Это отчасти верно. Тем не менее, какими бы позитивными они ни были, стереотипы остаются неизменны, и вы всегда будете не в состоянии понять всю картину происходящего, используя их.

Стереотип как феномен рассматривается с разных точек зрения. Неоднозначно и отношение к стереотипам. Например, О.А. Леонтович считает, что «стереотипы - упрощенные ментальные репрезентации различных категорий людей, преувеличивающие моменты сходства между ними и игнорирующие различия. «Стереотипизация» предполагает статичный взгляд на общество и человека, неумение воспринимать уникальность человеческой личности, стремление свести всех людей к ограниченному числу типов со стандартным набором характеристик» [4, с. 236].

Определение О.А. Леонтович дано в контексте проблем межкультурной коммуникации. О.А. Леонтович считает, что «различные виды стереотипов, существующие на уровне языка, способны создавать помехи в межкультурном общении» [4, с. 240]. Но это не совсем справедливо по отношению к стереотипу, (мы придерживаемся мнения, что стереотипизацию нельзя рассматривать как однозначно отрицательное явление.

С.Г. Тер-Минасова утверждает, что, несмотря на схематизм и обобщенность, стереотипные представления содержат первоначальные знания о других народах и других культурах и тем самым подготавливают почву для общения с ними, смягчая культурный шок.

A.В. Павловская также отмечает положительную роль стереотипов: «Стереотипы позволяют человеку составить представление о мире в целом, выйти за рамки своего узкого социального, географического и политического мира» [5, с. 17].

Е.И. Рогов определяет стереотип как «устойчивый и в то же время упрощенный образ какого-либо явления в условиях нехватки информации. Именно стереотипы позволяют человеку существенно сократить время реагирования на изменяющуюся реальность, ускорить процесс познания» $[7$, с. 193].

Нельзя отрицать положительную роль стереотипов в межкультурном общении. Попадая в незнакомую этническую среду, человек может испытать культурный шок. При всей своей схематичности и обобщенности стереотипные представления о других народах и других культурах подготавливают к столкновению с чужой культурой, ослабляют удар, уменьшают культурный шок. Кроме того, стереотипы позволяют получить базовые фоновые знания о стереотипных представлениях и поведении в разных культурах, что очень важно для успешного осуществления процесса коммуникации без конфликтов, недопонимания и неловких ситуаций.

Нельзя переоценить важность национально-детерминированных представлений о предмете или ситуации, а также особенности поведения представителей разных культур в деловой среде. Это имеет отношение и к деловому этикету, и к продвижению товаров на международном рынке. Многие специалисты в области маркетинга подчеркивают необходимость изучения мнения потребителей о продуктах, произведенных в других 
странах. Эти мнения часто формируются на основе стереотипных представлений об этих странах. Например, Германия ассоциируется с надежностью и высоким качеством, Япония - с передовыми технологиями в электронике, Франция - с хорошим вином и парфюмерией. Поэтому понимание того, как потенциальные потребители воспринимают страну и культуру производителя продвигаемого продукта, является эффективным ходом в маркетинге. Однако, в межкультурном общении не следует полагаться только на стереотипы. Они должны рассматриваться лишь как фактор, дающий первичное представление о том или ином народе. В процессе общения подобное представление может существенно измениться.

Непроизвольная фиксация на уже имеющемся стереотипе серьезно затрудняет наблюдение за реальными действиями партнеров, и в этом случае стереотип действует как коммуникационный фильтр, «отсеивая» те моменты действий, которые не соответствуют стереотипу. Таким образом, стереотипы ведут к некоторому искажению реальности и включению в процесс общения своеобразного «автопилота», который предполагает жесткую схему восприятия и существенно затрудняет или даже совсем исключает обратную связь с партнерами по коммуникации. Следствием этого, как правило, является то, что действительное поведение партнеров, как и их намерения, остаются незамеченными или неправильно понятыми, что оказывает влияние на ход общения и может стать источником конфликтов. Поэтому проблема построения адекватного поведения с учетом существующих стереотипов актуальна.

В более широкой перспективе, особенно в многокультурном обществе, поддержание позитивных стереотипов одной конкретной группы подчеркивает негативные стереотипы других (например, они ленивы; они зависят от благосостояния; они преступники и т. д.). На самом деле, это может способствовать правовой несправедливости, социальной враждебности, расовой ненависти, созданию платформ для обвинения других групп в том, что они не являются образцом, что не со- ответствует уровню их вклада в социальное развитие общества. Но что, если рассмотреть стереотип в противоположности с понятием культурного факта. В этот момент критически настроенный человек задаст вопрос: «Как я могу отличить стереотип от факта?» Существует огромная разница между стереотипом и точным описанием культуры.

Полезно помнить, что предубеждения основаны на восприятии, а точное культурное описание основано на исследованиях.

\section{Выводы}

Повышение межкультурной осведомленности подразумевает развитие навыков успешного общения, то есть компетентного и мирного взаимодействия с людьми, которые отличаются от нас. Такой подход назначает другую важную роль учителя / ученика иностранного языка: роль «межкультурного посредника», то есть человека, способного критически осмыслить отношения между двумя культурами. Очевидно, что не всегда легко собрать всю информацию, чтобы определить, является ли часть информации фактом или стереотипом.

Однако мы знаем, что это возможно. В конце концов, стереотипы и предрассудки повсюду, и мы не можем их избежать. Мы даже не можем избежать их непосредственного воздействия.

Тем не менее, у нас есть выбор не воздействовать на них и даже лучше, регулировать наше собственное поведение и непосредственно способствовать этому может обучение межкультурной коммуникации. Ведь как показывает практика, эффективное межкультурное общение требует сочувствия, уважения, открытости и чуткости.

Преподаватели в свою очередь должны создавать условия для общения, основанные на общечеловеческих ценностях, культурных нормах и потребностях учащихся, а не на учебных планах и текстах / учебниках, разработанных носителями языка.

\section{ЛИТЕРАТУРА}

1. Harlan Cleveland, "The limits of Cultural Diversity», in Intercultural Communication: A Reader, 9th ed., L.A. Samovar and R.E. Porter, eds. (Belmont, CA: Wadsworth, 2000), 427.

2. Douglas Martin, Jacqui Hutchison, Gillian Slessor, James Urquhart, Sheila J. Cunningham, and Kenny Smith, «The Spontaneous Formation of Stereotypes Via Cumulative Cultural Evolutiono» Psychological Science 25, no. 9 (2014): 1777-86.

3. Jeffrey W. Sherman, Frederica R. Conrey, and Carla J. Groom, «Encoding fl exibility revisited: Evidence for enhanced encoding of stereotype-inconsistent information under cognitive load», Social Cognition 22, no. 2 (2004): 214-232.

4. Леонтович 0.А. Русские и американцы: парадоксы межкультурного общения: Монография. Москва: Гнозис, 2005. 352 c. 5. Henri Tajfel and John C. Turner, «An integrative theory of intergroup confl ict», The social psychology of intergroup relations 33, no. 47 (1979): 74.

5. Павловская А.В. Россия и Америка. Проблемы общения культур. М.,1998. С. 17 
6. David M. Amodio, «The neuroscience of prejudice and stereotyping» Nature Reviews Neuroscience (2014): 670-82.

7. Рогов Е.И. Общая психология. Курс лекций. Ростов: Изд-во «Владос-Пресс», 2006. С.193.

8. Robert M. Baird and Stuart E. Rosenbaum, eds., Hatred, bigotry, and prejudice: Defi nitions, causes, and solutions, (Prometheus Books, 1999$), 130$.

9. Colin Simpson, «Good Salary, Depending on Where You're Coming From» TheNational, April 272012.

10. Loriann Roberson, Elizabeth A. Deitch, Arthur P. Brief, and Caryn J. Block, "Stereotype threat and feedback seeking in the workplace» Journal of Vocational Behavior 62, no. 1 (2003): 176-188.

( ) Кривошеева Елена Николаевна (krivosheeva.elena.1969@mail.ru), Луковцева Виктория Николаевна (luvina@mail.ru).

Журнал «Современная наука: актуальные проблемы теории и практики»

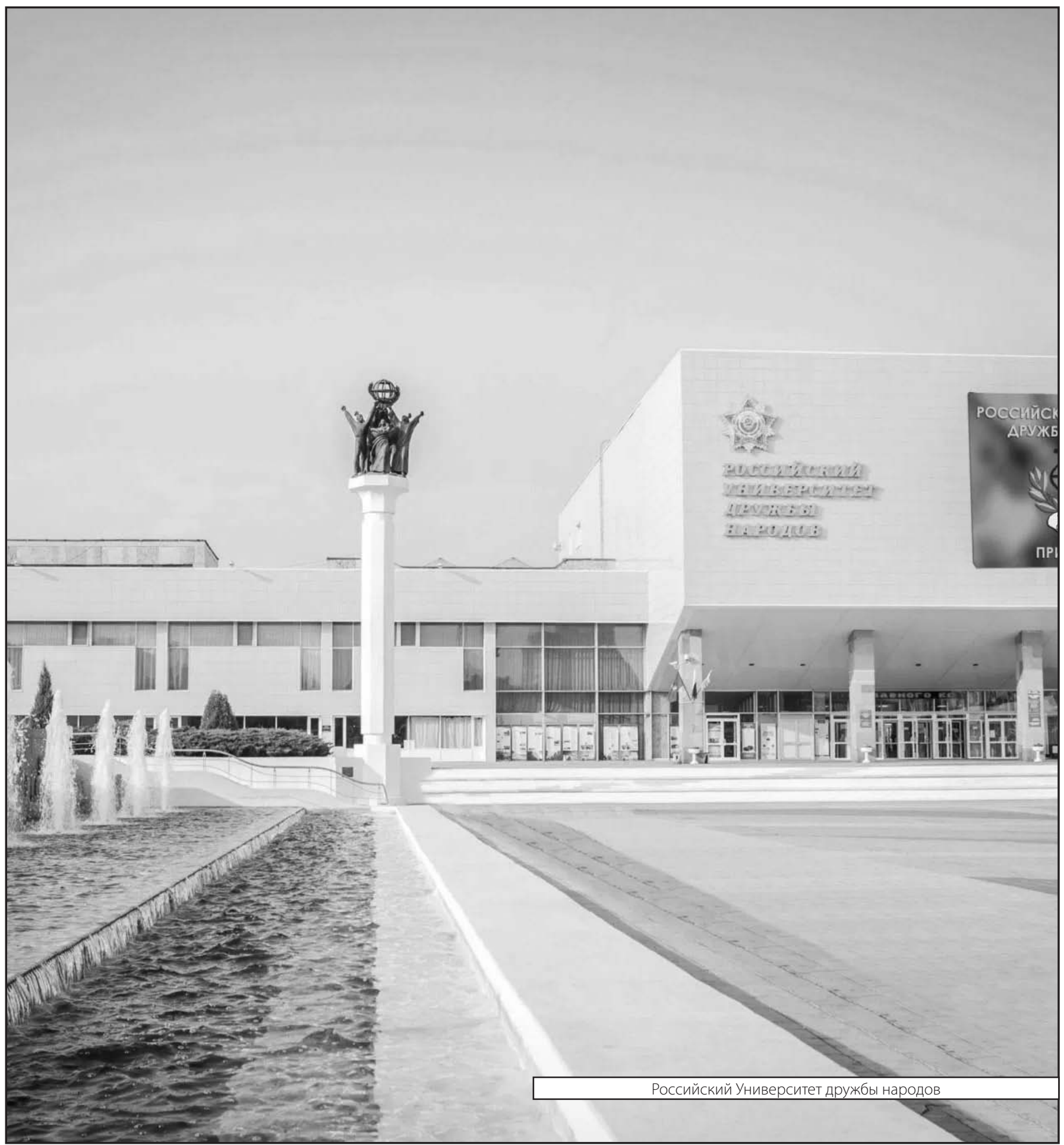

